\title{
NARRATIVE LUDOLOGY: INTERMEDIALITY IN ADVENTURE GAMES
}

\author{
Pedro Groppo
}

Doutorando Literatura Comparada do Programa de Pós-Graduação em Estudos Literários /

UFMG

\begin{abstract}
This paper proposes to discuss how adventure games, a subgenre of video games, have become a new medium that manages to combine elements from literature, comics, and movies in order to present highly complex interactive narratives of their own. The phenomenon of intermediality within this plurimedial medium is discussed using Irina Rajewsky's definitions of medial transposition, media combination and intermedial reference.
\end{abstract}

\section{KEYWORDS}

Narrative, intermediality, interactivity, videogames

More so than in any other medium, the possibilities of what can be conveyed and done in videogames are dictated by technology. Cinema is also highly dependent on the available technology of the time, but its language was largely established in the silent era, in the early 20th century. Videogames, while borrowing from other media, mainly cinema and literature, have been developed only for a few decades, and due to the rapid development of computer technology, a short span of as little as five years can open up whole avenues of game design.

Since very little has been written about adventure games, the purposes of this paper will be to describe them, their intersections with other media, and the possible implications the new medium of games introduce to this field of study. I will be adopting Irina Rajewsky's definitions of medial transposition, media combination and intermedial reference ${ }^{1}$ to allude to the phenomenon of intermediality within this plurimedial medium. Medial transposition is about the transformation of one product to another, e.g. adaptation. Media combination involves two or more media for the constitution and significance of one product, whereas

\footnotetext{
${ }^{1}$ RAJEWSKY. Intermidialidade, intertextualidade e "remediação": uma perspectiva literária sobre intermidialidade, p. 9.
} 
intermedial reference evokes or imitates techniques of or alludes to another medium. ${ }^{2}$ As we will see, adventure games are in their majority working within the latter two categories proposed by Rajewsky, and often within all three.

The majority of videogames are action-based. The most iconic and famous examples are still from its early days, such as Tetris, Pac-Man and Super Mario. Even though videogames have appropriated some level of narrative to convey some kind of backstory, in actual experience, they bear little or no relation to the gameplay itself. Super Mario has a simple backstory, but it is inessential to the understanding of how the game works and its objectives. The story is: Mario (the protagonist) must cross through worlds, defeat enemies and rescue a kidnapped Princess. In early videogames, probably because of limitations of size, there was no attempt to convey this, and the player could only infer the objectives of the game, mainly through trial and error. Videogames work mainly by a system of reward and punishment. If the player does something wrong, his progress is halted and he has to start over. $^{3}$ On the other hand, the player is rewarded by a number of ways, ${ }^{4}$ the most important probably being the ability progress through the game. As systems became more advanced, narratives began to play a larger role in all kinds of games. Only more abstract games such as Tetris, a puzzle game in which geometrical blocks fall from the top of the screen and most be paired with others so that they disappear before the screen fills up, cannot be said to have a narrative. Tetris, notably, does not feature a stand-in for the player, as there is no recognizable human presence or character. As long as there is some kind of player stand-in in the form of a main character, narrative plays a major role in videogames.

To say that a game is action-based implies that the player has limitations, often of time, to complete its goals. He must have some amount of skill and familiarity with the controls to be able to avoid enemies or obstacles that thwart his progress. A good example is the Mario series, which belongs to the "platform” subgenre, in which the player's avatar can move in two dimensions and jump over obstacles and enemies to progress (usually to left to right). The challenge of the game lies in being able to successfully navigate each level without

\footnotetext{
${ }^{2}$ RAJEWSKY. Intermidialidade, intertextualidade e "remediação": uma perspectiva literária sobre intermidialidade, p. 10.

${ }^{3}$ Actually, Jesper Juul describes different types of punishment for player failure: "energy punishment; life punishment; game termination punishment; and setback punishment” (JUUL. Fear of failing? The many meanings of difficulty in videogames, p. 238).

${ }^{4}$ Hallford e Hallford list four general types of rewards in computer role-playing games. These categories are "rewards of glory, rewards of sustenance, rewards of access and rewards of facility" (HALLFORD; HALLFORD. Swords and Circuitry: a designer's guide to computer role playing games).
} 
dying. There is no need to know or follow a narrative to progress through a game of this genre, as the objective remains the same no matter what stage the player is in or regardless of his actions. Newman writes, “[t]ypically, videogames create 'worlds', 'lands' or 'environments' for players to explore, traverse, conquer, and even dynamically manipulate and transform...” 5 Even though the game system has many ways to reward the player, ultimately, it is the unlocking of new levels that propels the game forward. In many games of this kind, the sign that game is over is that instead of a new level, the player will find an animation that will conclude the story. In games that allow players to move through the z-axis into three-dimensional worlds, often called "first person shooters" such as Wolfenstein $3 D$ and Doom, the very essence of the gameplay is the navigation through space, the narrative usually involving the player/character facing some kind of maze.

Jesper Juul writes that videogames, unlike cinema or literature, need not have points of identification. Cinema and indeed, most narratives are largely about humans and antropomorphic creatures that the viewer or reader identifies with cognitively. Games, on the other hand, do not have these actors, ${ }^{6}$ Tetris being one example. Whereas many games have had their cinema adaptations (Mortal Kombat, Tomb Raider), and their characters and story have gained significantly in detail in the adaptation, this does not seem to be necessary for most videogames. For Juul, the player is always constant, and the reader/viewer (of films or books) needs an emotional motivation for investing energy in the movie or book; we need a human actant to identify with. This is probably true for the computer game, only this actant is always present - it is the player. The player is motivated to invest energy in the game because the game evaluates the player's performance. And this is why a game can be much more abstract than a movie or a novel, because games involve the player in a direct way. ${ }^{7}$

Juul seems not to be dealing with adventure games. Even though there are moments inside the game in which there is no narrative, an adventure game without a plot or characters is inconceivable. It is no wonder, therefore, that the adventure genre is so different than other games. The adventure rarely "evaluates the player's performance,” for instance, and unlike the action game, an adventure is not based on fast reflexes; the time of the adventure game is on pause when the player does not do anything. They depend upon narratives and their objectives are dynamic. Here the rules, the rewards and punishment, and goals are intrinsically linked to

\footnotetext{
${ }^{5}$ NEWMAN. Videogames - routledge introductions to media and communications, p. 108.

${ }^{6}$ JUUL. Games telling stories? A brief note on games and narratives.

${ }^{7}$ JUUL. Games telling stories? A brief note on games and narratives.
} 
a narrative. The reliance on a well-developed narrative has approximated this genre of games to its models, namely literature and cinema. Popularly, the genre has at times been called “interactive fiction” and "interactive movie," and some of the more accomplished titles arguably deserve the monikers.

The adventure genre can be defined by its gameplay, rather than its contents or theme. Gameplay involves solving puzzles, which can range from the simple jigsaw puzzle to fullfledged enigmas with multiple locations and puzzles within puzzles. For his or her success, the player is rewarded new areas to explore, new items or clues to collect, but ultimately, it advances the story. Whereas the videogame format allows some level of non-linearity, adventure games are essentially linear and follow a previously written plot. The player's entire motivation to play is to get to the end of the story, as in any kind of narrative. Adventure games rely on what Roland Barthes defined as the "proairetic code" (i.e. a structuring principle that builds interest or suspense; an action that implies a further narrative action). ${ }^{8}$ Even though some of these games have a scoring system, it rarely affects the player's progress or the narrative.

Because of technical restrictions, the first adventure games, released in the late 1970s, did not contain graphics, and were only comprised of text. Immediately the genre was approximated to literature and received the moniker of "interactive fiction," for which they are still known. These rudimentary "interactive fictions" owed a great deal to the style of “role-playing game” developed with Dungeons \& Dragons, a fantasy board game that relied heavily on the player's imagination. The first text adventure, Adventure, was released in 1977. The game world and its actions are textually described, and the player must interact with this world using a text parser, by typing expressions such as "go north" or "pick up sword.” The fact that computers had only a keyboard for user input certainly shaped this design choice.

Beginning a game of Adventure often looks like this:

Welcome to Adventure!

(...)

At End Of Road

You are standing at the end of a road before a small brick building. Around you is a forest. A small stream flows out of the building and down a gully.

>enter building

Inside Building

You are inside a building, a well house for a large spring.

There are some keys on the ground here.

\footnotetext{
${ }^{8}$ BARTHES. S/Z, p. 18.
} 
There is tasty food here.

There is a shiny brass lamp nearby.

There is an empty bottle here.

>get lamp

Taken.

The player is able to identify objects he or she can interact with ("building," "keys”) and must use his or her imagination and linguistic skills to be able to convey the right expression to the computer. In the example, sentences beginning with ">” mark a player input. As technology progressed, text parsers were able to allow an increasingly greater number of permutations and ways of conveying the same action. But the player needs to choose the right verb and word construction. Interaction with the game is severely limited by linguistic constraints, and it can be said that the player's role is to feed the computer the right lines at the right time. The text adventure game, therefore, is little more than an open, nonlinear novel, and one can be often frustrated as she or she struggles to verbalize actions in the phrasing the system expects. It is worth noting that in these early incarnations, the narrative is often in the second person, and the player is put in a central position. In addition, it was common practice for players to make copious notes and draw maps of the game areas. This shows there was a great level of involvement in the part of the player, especially in terms of time and attention dispensed to reading, and a level of intimacy that is often associated with literature.

Well through the 1980s, before graphics displays and processors were advanced enough, adventure games were little more than a computer-based version of the popular Choose Your Own Adventure series of children's books. These were written also in the second person, with the reader assuming the role of the protagonist and making choices that determine the main character's actions and outcome. The relation between the player and the game world is purely text-based. Graphics were introduced in the late 1970s to the genre, but at first, they were only used to supplement the text descriptions, and interaction was still limited to the text parser, as in the popular series King's Quest (1984). Even though there was a pictorial dimension to the game, the player often had to enter a command such as "look" (in King's Quest, for instance) so that the image could be described and the player could recognize the keywords the system expects, a phenomenon often referred to as "syntax guessing." For example, in the first screen of the King's Quest game, the protagonist is in front of a castle and to enter, he needs to open the gate. If for some reason the player enters "open door" or any other phrase that is not "open gate," the system will not advance the game. A command such as "look" is useful because it would describe the graphics in textual 
form, so that the player can enter it back into the text parser. Therefore, even though King's Quest and other games of the period are graphical, they still need to be reduced to the textual dimension to be played. Because the graphics are so rudimentary, often players would not recognize the pixels as a specific object, and therefore resorting to the textual description was needed.

With the advent of another kind of input device, namely the mouse, players were able to interact with the game world in a new way. With the mouse and more complex graphics, developers could do with the text parser altogether, making players use the mouse pointer to interact with objects or characters onscreen. The textual dimension remained, however. In games such as Maniac Mansion (1988) and a number of others that succeeded it, what can be termed a "verb matrix" is present onscreen as a graphical interface. Verbs, (e.g., talk, walk, open, use) or symbols that refer to it (e.g., a mouth, legs, or a hand) are represented onscreen. To interact, players must still construct verb-noun phrases, by clicking first on the verb and later on the object or character. Games with this sort of interface are less frustrating in a certain sense than those which depend on a text parser, because the player is not required to partake on a linguistic guessing game. The limitation of the system is apparent, however, in a common occurrence called "pixel hunting," in which the player must position the mouse pointer on objects that are too small or well-hidden, a situation that can be equally frustrating.

With more advanced graphics, puzzle design became more complex, and some game designers have managed to develop a new kind of gaming experience. Titles such as Myst (1993) are famous for their non-verbal approach. There is a great emphasis on puzzle-solving, and little is known of the back story and characters. In Myst, the main character is the player him or herself, who must gather mostly non-verbal clues to solve puzzles and travel between worlds. Structurally, Myst is quite close to Adventure. The player explores a world and solves a number of puzzles. The frame story, explained in the manual, is as follows:

You have just stumbled upon a most intriguing book, a book titled Myst. You have no idea where it came from, who wrote it, or how old it is. Reading through its pages provides you with only a superbly crafted description of an island world. But it's just a book, isn't it? As you reach the end of the book, you lay your hand on a page. Suddenly your own world dissolves into blackness, replaced with the island world the pages described. Now you're here, wherever here is, with no option but to explore... ${ }^{9}$

Ads for Myst - notably one of the most popular adventure games ever - reflected this turn from action and towards exploration: “Myst is real. And like real life, you don’t die every

\footnotetext{
${ }^{9}$ Cited by JUUL. Fear of failing? The many meanings of difficulty in videogames.
} 
five minutes. In fact you probably won't die at all. The key to Myst is to lose yourself in this fantastic virtual exploration and act and react as if you were really there." ${ }^{10}$ Even though the game has set goals, they do not convey accurately the experience of playing it. The player is able to navigate in a three-dimensional game world, and the majority of the gameplay consists of a spatial exploration of that world, and the search for items and clues on how to piece together the backstory and the objectives of the game. In games such as Myst, space and setting seem to have a greater role than plot or character, and they take their cues less from literature but from architecture and geography. It is interesting that without these goals there would be no point in playing more open-world games such as Myst. It is in the very nature of video gaming that they rely on the need to fulfill a goal and on a whole system of rewards. Even in a more exploratory game there are artificial limitations to which spaces you can explore, and these are triggered by the player's success and failure. There are a set of games that exist in the category defined by Jesper Juul as "open and expressive games, games that let the player use them in many ways, games that allow for many different playing styles, for players pursuing personal agendas.”11 Even more simple games, such as a Mario game can be played in this manner, the player setting his or her own goals (for instance, completing a level within a time limit), open-world games, also called "sandbox," such as Myst, allow an experience that has little to do with rules or narrative. The exploration of the game world, even though it depends on certain game rules, can also become a sort of virtual reality, a simulated space in which the player can explore without observing the set rules and objectives of the game.

More recent games have been able to recreate real-world environments. One notable example is 2011's L.A. Noire, which recreates an area of approximately 8 square miles of downtown 1947 Los Angeles, complete with landmarks and period vehicles. Even though there are reports of a faithful, historic reproduction, the world the game is really trying to reproduce is a fictional one, the Los Angeles of the hard-boiled fiction of Raymond Chandler and film noir. Since the game is about being a LAPD detective solving crimes, it does not matter if the game gets the historical Los Angeles right, it is successful if it can manage to tap into the player's familiarity with the genre, revealing a true intermedial aspect. Clearly $L . A$. Noire does not purport to be a historical document, but it does not aim to be an interactive movie either. Large portions of the game involve driving around the city, an experience that

\footnotetext{
${ }^{10}$ JUUL. Fear of failing? The many meanings of difficulty in videogames.

${ }^{11}$ JUUL. Without a goal: on open and expressive games, p. 191.
} 
has no real counterpart with literature or film. The player is even rewarded for exploring every inch of it. Other elements are markedly more intermedial, such as interrogating suspects - other than being able to choose if an interviewee is being lying or truthful, one can only watch. The technology used in the game makes it apparently very close to cinema - similar to the "full motion video" games of the 1990s - and the ability to explore a carefully reconstructed digital city is a new, twofold experience. In a way, it can enrich the player's relationship to the seedy, noir world as he or she is able to take in a more complex environment. From the arts, other than through some off-hand remark by Philip Marlowe in Chandler or close observation of some films, people unfamiliar with Los Angeles might not be aware of the distance or the relationship some areas and places have with one another. Sometimes these are vague associations, but it might be illuminating to observe the distribution of wealth or social segregation, for instance, in a space such as this. This is something neither literature nor cinema can do, because literature lacks the visual aspect, and at least in commercial cinema it would take too much time. Only Jacques Rivette, in France, treats space in a way that might come close to an in-game exploration, and even so it would not be the same thing. In terms of intermediality, this is probably one of the most important aspects of the gaming experience, because this is something only videogames can provide the ability to tap and conflate a number of mediatic references from cinema, literature, architecture, design, music in a simulated space that has its own purposes. The intermedia aspect is not what the game is about; the game almost exists in spite of it.

It was only in 1990 that the first game was released with full dialogue recorded by actors (King's Quest V). Before that, games would employ 8 and 16-bit soundcards to play synthesized music and sound effects. The MIDI synthesized music was frequent, and some developers sought to take advantage of the full potential of the soundcards' digital sequencers, by creating a system (iMUSE) that would introduce musical motifs and gradually change the song depending on the location visited by the player. Voice and sound effects required more advanced soundcards, and these were only truly incorporated into the genre on the 1990s. An interesting, musically-themed adventure is Lucas Arts’ Loom (1990). Loom is not centered on interactions between the game character and the environment, but around four-note tunes or spells that the protagonist can play in his distaff and those have different effects, such as “opening” or "night vision.” Examining a blade while it is being sharpened, for instance, gives the player the "sharpening" spell. They take the form of musical note sequences on the C major scale, which is shown onscreen. Knowledge of musical notation is not required, but the notes are randomized and have to be learned each time the game is played. Some spells 
can be reversed by playing the notes backwards, so the opposite effect can be achieved, as it is the case of the "dye" spell, that played backwards becomes "bleach." This is an example of how the semantics of the word is transformed into a double code (the $\mathrm{C}$ major scale) and the actual musical notes, and the fact that it can be reversed to achieve the opposite effect attests to the flexibility of the intermedial transposition. Loom, with its ambitious plot, heavy with references to Greek mythology, and ingenious gameplay failed to make an impression on the gaming market, but it still remains on the most original games of the era.

Notably, Loom was accompanied by an audiotape containing a 30-minute audio drama recounting the backstory. It was not uncommon practice to include supplemental material in other media other than the game itself to convey additional details of the plot. Gabriel Knight: Sins of the Fathers (1993) included a full graphic novel narrating plot elements that are only alluded to briefly in the game, and its sequel, Gabriel Knight: Blood of the Sacred, Blood of the Damned (2000), lacked an opening sequence altogether, this being told also in a comics format inside the CD-ROM. Videogames, probably because many are already based on preexisting material (mainly movies) that the mixture of mediatic presentations is already a given. Infocom (responsible for titles such as Zork) started a tradition, now referred to as "feelies," of including extra material inside the game package. For instance, in the game James Clavell's Shogun (1989, itself based on a novel), the package contained a map representing the known world of 1600 (the time epoch of the game), and a booklet titled "The Soul of the Samurai," describe the history and significance of samurai swords. The "feelies" probably started as a means to evade copy protection, since it was easy for players to install the game in more than one computer. Sometimes the information was relevant and was required to complete of the game, such as in King's Quest III, which the manual contained recipes of the spells, or in Zork Zero, in which attempts to read a parchment inside the game will prompt the player to refer to the actual package. When they were not part of copy protection, these items worked as "value-added" and as incentives to buy the game, as if the complete experience of the game includes the use of the whole material included in the package, not only the software. An example of this is a copy of Indiana Jones's Grail Diary, a book present in the film and the game Indiana Jones and the Last Crusade (1989) and that was included within the game materials. The only other commercial media that comes to mind as a parallel are some LP records and CDs and some special DVD packages, but they are mostly decorative and far less integrated with the actual mediatic presentation itself than in computer games. 
Some adventure games are direct transpositions of a work from another medium. Notable examples are a game based on H.P. Lovecraft's Shadow of the Comet, The X-Files (based on the TV series), and Blade Runner. The latter title is particularly interesting because the game is not a direct adaptation of the 1982 movie, but a story that takes place in the same settings, with a couple of overlapping characters; a story that happens simultaneously, on the fringes of the movie. It succeeds in capturing the appearance of the Blade Runner universe, but if it were not for some visual and textual allusions to the Ridley Scott movie, it would be nothing more than a pastiche. The X-Files is another full-motion video game and even features some of the actors of the TV series, in a clear attempt to capitalize on the series' success, and holds very little interest of its own. As a matter of fact, probably since Star Wars, videogames have profited from licenses from known movies, TV or comics, and most of them provide little more than a certain nostalgia, a joy triggered by the memory of the title it originated from. Even though there exist titles that follow the plot of the adapted material closely (e.g., the text adventure The Hobbit, based on J.R.R. Tolkien's novel), it is clear that in the transposition between media, it is not important, or even desirable to maintain plot, but the characters and settings. To employ Seymour Chatman's terms, to keep the existents but to alter the events. ${ }^{12}$ Thus, the experience of a book or a movie can be expanded so as to include entries in more than one medium. As it is the case of novelizations of films, the success of which can only be explained by the reader's desire to revisit a film from another perspective, some games can be placed in this category of an expanded, plurimedial experience. It is not enough to watch a movie, but to read the book, play the game, and listen to the soundtrack. Even though this multimedia offering may vary in quality, they remain valid and should never be studied separately.

Some adventure games feature at is termed a "dialogue tree," in which the player can choose topics or full sentences, in order to best communicate with another character. Because of the high textual content the player must face, this may look closer to literature, but what the right dialogue choices often trigger, as well as the right solution to puzzles, are the so-called “cutscenes," an animated or live-action sequence that advances the plot. Cutscenes are an example of how videogames can be a container for other media: a moment in which the game interrupts its flow and becomes, temporarily, another medium (that of cinema). With the advent of the high storage capacities of the CD-ROM in the early 1990s, game designers jumped at the possibility of making “interactive movies,” with mixed results. Videogames are

\footnotetext{
${ }^{12}$ CHATMAN. Story and discourse: narrative structure in fiction and film, p. 19.
} 
not fulfilling their whole potential when they are only mimicking other media, and some of these games (Phantasmagoria, The 7th Guest) do not do much more than allow the player to trigger one cutscene after another, with only a few too simple puzzles in between. As Juul argues:

Games and narratives share some structural traits. Nevertheless, my point is that: 1) Games and stories actually do not translate to each other in the way that novels and movies do. 2) There is an inherent conflict between the now of the interaction and the past or "prior" of the narrative. You can't have narration and interactivity at the same time; there is no such thing as a continuously interactive story. 3) The relations between reader/story and player/game are completely different - the player inhabits a twilight zone where he/she is both an empirical subject outside the game and undertakes a role inside the game. ${ }^{13}$

Even though Juul is not dealing specifically with adventure games, he does raise important concerns. Cutscene (as well as the opening and ending sequences) are games at their most narrative, and at the same time, least interactive (there is no player involvement). Juul argues that there is no narrative and interactivity at the same time. Effectively, the cutscenes interrupt the game and introduce another kind of medium. There are even reports that players change their body posture when a cutscene is triggered - they tend to lean back, as less attention seems to be required of them. There is also the problem of game-time (or discourse-time, to use Genette's terms) versus story-time. ${ }^{14}$ Adventure games, in contrast with action games, often function on a paused environment, where little, other than expected timed actions in certain games, ocurrs. Other than that, the player is free to explore and take his or her own time to solve puzzles, look around and interact with other game elements. Since time is so dilated, a great amount of attention must be given to space.

Gabriel Knight: The Beast Within is an example of how the "interactive movie" format could succeed, because it manages to combine the live-action cutscenes with a rich and demanding plot. It is one of the most interesting games of the genre because it provides a forceful combination of other media (the story converges on a Wagner lost opera and King Ludwig II of Bavaria), history, and a strong sense of setting. Real-world locations were used, such as the Wagner Museum in Bayreuth and Ludwig's Neuschwanstein Castle, and as I argued before, exploration being one of the mainstays of the genre, setting can be just as important as plot. The two other games of the Gabriel Knight series also excel at this, being

\footnotetext{
${ }^{13}$ JUUL, Games telling stories? A brief note on games and narratives.

${ }^{14}$ GENETTE. Narrative discourse, p. 34.
} 
set in the French Quarter of New Orleans and in the Rennes-le-Chatêau area in France. Even if the locations depicted in those games are far from detailed and accurate, they do provide, as with L.A. Noire, a unique way of conveying background information and flavor to the player. Since so much more time is spent playing and navigating these spaces than watching a movie or reading spatial descriptions in fiction, this seems to me to be one of the crucial aspects of this genre of videogames, and the success or failure of a game can be directly influenced by its setting and ambiance, precisely because there time is expanded.

In conclusion, I would like to point out that this has been nothing more than a cursory overview of adventure games, their features, narratives, and their relation to other media. A much more detailed study would be required to thoroughly explore all the areas opened up and suggested by this brief discussion. Although not all games depend on narratives, adventure games do, and even though it may appear that the adventure player is more passive than usual, his involvement in the game is precisely what Rajewsky described as a combination of media. An adventure game player is intermedial by nature: he is invested in a fictional narrative that may have begun on a short film on CD-ROM, a comic included in the game package, or a short story. Gameplay involves the more abstract act of puzzle-solving, but they can range from a simple jigsaw puzzle to complex mini-games with language, sound, and visuals. And there is of course the underlying gameplay aspect that is required of the player: contrary to what Juul argues, games do tell a story. The American playwright and computer theorist Brenda Laurel proposes a system for generating well-formed plots as defined by Aristotle in his Poetics. ${ }^{15}$ In this proposed system, the computer program must take on the role as author while the game progresses. Any action by the player must lead to the system adapting the fictive world so as to make sure every story is well formed. In adventure games, it is up to the player to figure out what this narrative is, and keep advancing it until the end. The order in which the events of the narrative occur vary, immensely, and only the most linear games will not allow some degree of leeway to the player in this aspect. It is probably the factor of non-linear storytelling, along with the possibilities of exploration of simulated space that make gaming such a unique experience that so far, no other medium can replicate.

\footnotetext{
${ }^{15}$ LAUREL. Computers as theatre, p. 135-142.
} 


\section{RESUMO}

Este artigo se propõe a discutir como um subgênero de jogos eletrônicos, assim chamado os adventure games, compõem uma nova mídia que combina elementos da literature, quadrinhos e do cinema para apresentar narrativas complexas e interativas. O fenômeno da intermidialidade é discutido usando as definições de Irina Rajewsky sobre transposição, combinação e referência.

\section{PALAVRAS-CHAVE}

Narrativa, intermidialidade, interatividade, videogames

\section{REFERENCES}

BARTHES, Roland. S/Z: an essay. Trans. Richard Miller. Nova York: Hill \& Wang, 1974.

CHATMAN, Seymour: story and discourse: narrative structure in fiction and film. Ithaca: Cornell University Press, 1978.

GENETTE, Gerard. Narrative discourse. Ithaca: Cornel University Press, 1980.

HALLFORD N.; HALLFORD, J. (Ed.). Swords and Circuitry: a designer's guide to computer role playing games. Roseville, CA: Prime Publishing, 2001.

JUUL, Jesper. Fear of failing? The many meanings of difficulty in videogames. In: PERRON, B.; WOLF, M. J. P. (Ed.). The Video Game Theory Reader 2. Nova York: Routledge, 2009.

JUUL, Jesper. Games telling stories? A brief note on games and narratives. Game Studies. v. 1, n. 1, July 2001.

JUUL, Jesper. Without a goal: on open and expressive games. In: ATKINS, B.; KRZYWINSKA, T. (Ed.). Videogame, player, text. Manchester: Manchester University Press, 2007.

LAUREL, Brenda. Computers as theatre. Reading, MA: Addison-Wesley, 1991.

NEWMAN, James. Videogames - Routledge introductions to media and communications. London: Routledge, 2004.

RAJEWSKY, Irina O. Intermidialidade, intertextualidade e "remediação": uma perspectiva literária sobre intermidialidade. Trad. Thaïs Flores Nogueira Diniz e Eliana Lourenço de Lima. Reis. In: DINIZ, Thaïs Flores Nogueira (Org.). Intermidialidade e Estudos Inter-Artes. In press. 